\title{
PESQUISA ESCOLAR SIGNIFICATIVA E O BIBLIOTECÁRIO: QUESTÃO ESSENCIAL PARA A INFOEDUCAÇÃO
}

\author{
INVESTIGACIÓN ESCOLAR SIGNIFICATIVA Y EL \\ BIBLIOTECARIO: CUESTIÓN ESENCIAL PARA LA \\ INFOEDUCAÇÃO
}

Ivete Pieruccini*

\begin{abstract}
RESUMO:
Introdução: A pesquisa escolar e as dificuldades para torná-la prática qualificada e efetiva no cotidiano da educação de crianças e jovens, em nosso país, é tema recorrente tanto para bibliotecários, como para professores e demais educadores em geral.
\end{abstract}

Objetivo: A partir da problematização de enfoques que apontam causas de ordem pedagógica e metodológica para tais dificuldades, o artigo apresenta e defende a concepção de pesquisa significativa, noção que alarga perspectivas da pesquisa como ato de conhecimento pelos mais variados segmentos infantis e juvenis.

Metodologia: Ancorando-se nos fundamentos da Infoeducação, a noção de pesquisa significativa é discutida a partir do papel essencial dos dispositivos informacionais educativos e do bibliotecário, tomado como mediador cultural.

Resultados: $O$ estudo mostrou que a pesquisa significativa encontra-se em relação direta com os chamados dispositivos informacionais dialógicos, uma vez que tais instâncias de mediação cultural, por serem orientadas por princípios da apropriação informacional, conforme proposto pela Infoeducação, são capazes de resignificar relações dos sujeitos com a informação e o conhecimento. A ordem resultante das articulações entre ambiente, linguagens, repertórios, práticas informacionais e pedagógicas, nesses dispositivos, constituem mediações que favorecem processos de construção de vínculos entre os sujeitos e o conhecimento, implicando de modo específico os saberes e fazeres do bibliotecário, na contemporaneidade.

Conclusões: A noção de pesquisa significativa faz frente a situações em que crianças e jovens realizam buscas esvaziadas de sentido, restituindo ao ato de conhecer seu papel de ação sobre o mundo material e imaterial, objetivo e subjetivo, forma ativa e necessária à apropriação de informação, de sentidos, à construção de identidades. Trata-se de mudança paradigmática que envolve a redefinição de dispositivos informacionais educativos, tais como bibliotecas escolares e públicas (especialmente), tanto quanto o papel do bibliotecário, em contextos educativos.

* Docente no Curso de Biblioteconomia, do Departamento de Informação e Cultura (CBD) e do Programa de Pós-graduação em Ciência da Informação, da Escola de Comunicações e Artes, da Universidade de São Paulo, é coordenadora acadêmica do Colaboratório de Inforaducação, da ECA/USP. CV Lattes disponível em: http://lattes.cnpq.br/8007715109193414 
Palavras-chave: Pesquisa escolar. Pesquisa significativa. Infoeducação. Biblioteca escolar. Mediador cultural. Dispositivos informacionais educativos.

\section{INTRODUÇÃO}

Há décadas, a questão da pesquisa escolar é recorrente no país. Estudantes completamente perdidos, desamparados, sem saber por onde começar, vagueando perplexos diante de prateleiras cheias de livros, organizadas de modo incompreensível aos que não possuem as "senhas" de acesso aos mistérios dos conhecimentos ali armazenados, são evidências que marcaram no passado e permanecem ainda desafiando bibliotecários, professores e interessados em compreender e contribuir para a solução deste problema que afeta grande parte da nossa população de crianças e jovens. Por outro lado, observa-se, também, com frequência nos dias de hoje, alunos "pesquisando" absolutamente despreparados e afoitos diante do computador, na tão propalada prática do "recorta-cola-imprime".

Tais evidências apenas indicam dificuldades dos estudantes que, apesar do esforço que possam realizar indo, sobretudo, até à biblioteca ou enfrentando a complexa avalanche informacional disponível na internet, acham-se numa situação em que as informações lhes são estranhas. Marinheiros sem bússola, lançados à deriva nos oceanos do conhecimento, não admira, pois, que acabem sobrevivendo à contundente situação, somente aqueles que por razões excepcionais e muito particulares, diríamos, os «sortudos», conseguem ajuda especial, sejam estas de professores, bibliotecários, família, ou mesmo de colegas mais experientes.

De fato, a maioria das crianças e jovens encontra-se desarmada para a realização de pesquisas - da pesquisa escolar -, com reflexos sobre os processos necessários à construção de conhecimento, comprometendo, neste sentido, os projetos contemporâneos que aspiram mudar paradigmas educacionais, alicerçados em modelos pedagógicos transmissivistas.

A reflexão aqui proposta visa contribuir ao alargamento das abordagens vigentes sobre o tema, tendo-se como pressuposto que atos de conhecimento- 
tal como pressuposto na prática da pesquisa escolar - implicam sujeitos, tomados em toda sua complexidade, sem o que a apropriação das informações passa a ser apenas "belo discurso"... Entendemos, portanto, que o problema da pesquisa escolar, ainda uma questão essencial à Educação das novas gerações, ao contrário do que revelam alguns estudos (conforme discutido abaixo), demanda, sobretudo, uma noção norteadora, bem como, e em decorrência, dispositivos informacionais educativos, propriamente preparados ao desenvolvimento de saberes especiais e específicos, capazes de propiciar condições para que interesse e desejo de conhecer possam ser reconhecidos e alimentados nos e pelos alunos, desde sempre.

\section{Pesquisa escolar: percepções em torno do quadro de dificuldades}

Em trabalho recém publicado (OLIVEIRA; CAMPELLO, 2016), sob o título Estado da arte sobre pesquisa escolar no Brasil, cobrindo o período de 1989-2011, é apresentado um panorama analítico dos estudos sobre o tema em nosso país, a partir dos quais são apontados fatores, em tese responsáveis por emperrar e frustrar o desenvolvimento pleno da pesquisa escolar, especialmente no Ensino Fundamental. Estes fatores explicariam assim as razões pelas quais, apesar das longas décadas de debates e busca de alternativas para a questão, a satisfação dos alunos e profissionais (educadores, bibliotecários), bem como de pais, em relação à pesquisa escolar permanece como um devir...

Com base em 24 trabalhos (artigos em periódicos profissionais e especializados, dissertações, teses e comunicações em eventos, especialmente das áreas de Biblioteconomia/Ciência da Informação, Educação, Engenharia de Produção), a pesquisa buscou identificar aspectos relatados como problemáticos ao pleno desenvolvimento e incorporação da pesquisa escolar como prática educativa permanente e bem sucedida e em compatibilidade com grau de relevância que ela ocupa nos discursos dos profissionais. Os resultados gerais atribuem à pesquisa escolar uma série de problemas, dentre os quais: 
Malogro da pesquisa escolar como estratégia didática; Falta de questionamento e debates acerca da pesquisa; Falta de orientação pelo professor e pelo bibliotecário, ou precariedade dessa orientação; Prática recorrente da cópia pelos alunos; Falta de preparo do professor e do bibliotecário para orientar a pesquisa; Falta de preparo do aluno para empreender a pesquisa; Falta de interação entre bibliotecário e professor; Insuficiência das avaliações acerca da pesquisa efetuada; Falta de orientação para uso da Internet. (OLIVEIRA; CAMPELLO, 2016, p. 185-6)

Outros aspectos destacados ensejam que a falta de motivação do aluno para a pesquisa resulta dos modos como os temas surgem e são sugeridos pelos professores, o que também prejudica o interesse para o enfrentamento dos trabalhos. O uso da web, se não é mais visto como vilão da história (como em tempos anteriores) consegue atuar, pela natureza da tecnologia, na motivação de alunos (OLIVEIRA; CAMPELLO, 2016, p. 186-191), porém sem grandes méritos no que tange a impulsionar ou fazer os alunos lançarem-se sobre os desafios próprios aos processos de construção de laços com o saber.

Mesmo considerando-se que desde 1960, a biblioteca e os bibliotecários esforçam-se por conquistar papel fundamental nos processos de pesquisa escolar, atribuindo-se a eles a responsabilidade por atividades pedagógicas de "ensino da biblioteca" e de suas fontes, evidencia-se que muito pouco se avançou em termos de pesquisas capazes de explicar o fenômeno, apesar do aumento de estudos ligados aos cursos de pós-graduação no Brasil. (OLIVEIRA; CAMPELLO, 2016, p.182-3).

Parece, assim, que os discursos acerca do quadro problemático que envolve a questão, entre nós, não têm considerado as influências que uma dada concepção de pesquisa escolar e um determinado conceito de biblioteca vigentes podem significar na potencialização e atraso ao enfrentamento de dificuldades em relação a esta prática nos contextos escolares e culturais.

Consideradas as novas condições de acesso à informação na contemporaneidade, cada vez mais marcadas pela profusão, rapidez e facilidade com que os dados se oferecem e circulam, especialmente para uma grande parte da população, tais noções - de pesquisa escolar e de bibliotecaalém de indissociáveis, precisam ser problematizadas e revistas, tendo em vista que a construção de interesses e vínculos dos sujeitos com o 
conhecimento não se limitaria à oferta de signos, mas à criação de contextos favoráveis a esse diálogo. Não estariam aí algumas novas pistas para abordagem dos problemas acima relatados e para o papel do bibliotecário nesse quadro?

\subsection{Pesquisa escolar como busca e ato de conhecimento: o enfoque da Infoeducação}

O entendimento do que implica a prática da pesquisa escolar pode ser discutido a partir, primeiramente, de distinções em torno das noções de informação e conhecimento.

Peter Burke (2015, p. 83) retoma tais noções estabelecendo uma interessante analogia. Segundo ele,

Há diferentes distinções feitas por diferentes pessoas. Eu acho muito conveniente pensar que informação é relativamente crua (sic). Claro que não é completamente crua porque os seres humanos são programados para ver alguns aspectos do mundo e outros não. (...) Conhecimento, então, é a informação que foi processada. Gosto de utilizar a metáfora de Claude Lévi-Strauss, que diz que o conhecimento foi cozido e cozinhar significa "processar a sério".

Complementando, o autor considera que Conhecimento, em um estado relativamente cru, ou seja, a informação, "vem sem o entendimento, por isso, precisamos trabalhá-lo, dando-lhe significado, para que possamos, de fato, aprender com ele" (BURKE, 2015, p. 84). Sob tal perspectiva, o processamento da matéria simbólica (informação) implica sujeitos em processo de luta com o novo, o desconhecido, de forma, mais ou menos metódica, de acordo com os graus de interesse e possibilidades de cada sujeito. Podemos entender, assim, que tanto uma criança, empenhada em descobrir e compreender o que faz uma máquina a vapor andar, quanto um cientista em busca da cura de uma doença, encontram-se em situações semelhantes diante do "desconhecido" e do desejo de responder a indagações que Ihes sejam essenciais. 
Com o apoio das grandes narrativas, podemos avançar nessa ideia:

Contam as histórias que o herói se constitui sempre a partir de uma busca que ele empreende no intuito de encontrar a solução para algum problema, que não é seu somente, mas de seu grupo. Para enfrentar o desafio, ele é preparado recebendo instruções de pessoas experientes ou de entidades mágicas que o alertam e o orientam sobre os perigos de seu trabalho; de sua parte, o herói vasculha, dentre seus pares, buscando quem possa ensinar-Ihe algo novo, uma habilidade especial; observa como se comportam os melhores, os mais hábeis e inteligentes de seu grupo; mantém guardado um segredo ou talismã para ajudá-lo em momento crítico; reflete muito; imagina saídas ou soluções mirabolantes; concentra-se; desconfia das possibilidades ilimitadas de suas faculdades/capacidades; treina e confere tudo o que sabe e que tem acumulado. Depois, sai e põe em prática o que aprendeu para enfrentar os perigos. Seu percurso é marcado por inúmeros percalços que vão sendo vencidos, ou parcialmente perdidos, até a conclusão de sua tarefa. Ao término da saga, retorna finalmente transformado pelo processo que o faz detentor de um conhecimento, um saber que tão somente ele é possuidor, mas que compartilha com os seus ao voltar. A luta com o desconhecido é tratada como um momento de intensa produção, quando os sentidos, a cognição, o raciocínio, a imaginação, os afetos, as destrezas físicas são postas em funcionamento para enfrentar e chegar ao alvo desejado. A busca é, portanto, um procedimento fundamental do conhecimento em todas as suas dimensões, propiciando a apropriação do mundo e seus segredos pelo herói, bem como à constituição do herói como sujeito único e singular. O eu e o mundo se integram na e pela busca. (PIERUCCINI, 2004, p.32)

Pela metáfora do mito somos ajudados a compreender que a ideia de pesquisa, como verdadeira busca do sujeito, está intrinsecamente ligada aos atos de conhecimento, opondo-se, nessa perspectiva, à noção de automatismo dos comportamentos (às vezes desenfreados) de acesso e contato com informações, inscrevendo-se em dimensão que transcende à natureza instrumental, pragmática e superficial de pesquisa. Sob tal enfoque, pesquisar não é gesto simples, mera habilidade. Se o processo exige capacidade operatória superior, incluindo competências especiais e específicas, demanda, sobretudo, atitudes face à informação que contribuam para fortalecer o sujeito no desafiador processo de construção de significados para o Conhecimento. Questão complexa, esta noção de pesquisa implica 
igualmente as esferas da Informação e da Educação, em outros termos, a reordenação dos dispositivos de informação educativos, como as bibliotecas escolares, públicas e demais modalidades.

A significação da informação e do conhecimento está diretamente ligada à ideia de apropriação cultural, compreendida como ato de tornar próprio o que pertence a todos, por meio de negociações simbólicas (OLIVEIRA, 2014) variadas. Ao dar sentido às informações, significá-las, a partir da transformação do que é comum (a memória, o conhecimento) em algo que seja próprio e único, tal processo carrega, conforme visto na metáfora do mito, possibilidades de engajar os sujeitos na "luta pelo conhecimento", lançando-os não somente nas tarefas de localização e processamento de matéria cuja dimensão simbólica e destinos são por vezes indiferentes ou estranhos aos contextos de que participam, mas em movimento duplo e dinâmico de construção de identidades e, ao mesmo tempo, de criação de significados para o mundo. Por esta razão, a mera disponibilidade ou oferta de informações, tal como se tem hoje por meio do conjunto de diferentes recursos tecnológicos e computacionais para geração e uso da informação, pode funcionar em quadros em que o domínio dos instrumentos do conhecimento pelos sujeitos já se efetivou como, por exemplo, em contextos especializados. Sendo assim, um dos grandes desafios a serem encarados é o desenvolvimento das condições para a transformação da informação em bens simbólicos, em conhecimento, significação. Nesses termos, tomada como ato essencial, intrínseco à existência humana, a pesquisa (escolar), a busca de conhecimento é questão fundamental à Infoeducação, tendo em vista que os ambientes informacionais precisam considerar e incluir tais demandas humanas, objetivando-as em suas configurações materiais e nos seus modos de atuação, aspectos que afetam diretamente o bibliotecário. 
A abordagem da Infoeducação ${ }^{1}$, linha de estudos e de práticas socioculturais que se ocupam da dimensão formativa da informação (PERROTTI, no prelo), considera a pesquisa significativa como forma de diálogo dos sujeitos com os signos, modo de dar sentido às informações, de compreender e nomear o mundo. Nesse quadro, algumas categorias são especialmente consideradas, tais como a noção de sujeito do conhecimento, ou protagonista cultural; a noção de informação como signo, em suas diversificadas formas de representação do pensamento; a ordem informacional contemporânea e o quadro sociohistórico que a define e dinamiza, sobretudo a consideração dos contextos locais, como o brasileiro. Como prática, a pesquisa significativa faz parte, articula e articula-se a um conjunto mais amplo e complexo denominado Programa de Infoeducação (PERROTTI; VERDINI, 2008) que, ancorado em referenciais desta área, objetiva a constituição de saberes informacionais em nossa época (PERROTTI; PIERUCCINI, 2013)

\subsection{Pesquisa escolar e os dispositivos informacionais educativos}

Uma noção de pesquisa escolar como ato significativo difere, portanto, de perspectivas pelas quais historicamente esta foi e vem sendo tratada em nossas bibliotecas e escolas, ou seja, colocada como processo natural e espontâneo, por vezes residual e acessório, a ser desenvolvido independentemente das condições dos ambientes específicos para tanto. Talvez por isso, as queixas entre os envolvidos, confome sinalizado inicialmente, enfatizem tanto professores e bibliotecários e, muitas vezes, os próprios alunos.

Na perspectiva da pesquisa como parte dos processos de apropriação cultural, de construção de conhecimento e significação, todavia, há que se pensar na biblioteca para além de sua função de depósito, guarda e acesso à informação. Como um "dispositivo cultural", permeável às influências dos

\footnotetext{
${ }^{1} \mathrm{O}$ artigo que abre este número especial de Informação\&Profissões, de autoria do Prof. Edmir Perrotti, apresenta os princípios fundantes da Infoeducação e de suas relações com a Biblioteca e Educação.
} 
tempos, a biblioteca pode refazer-se, tendo por norte outro paradigma, ou seja, outro princípio norteador, alimentando-se de outros objetivos e perspectivas, resignificando seu papel de "mero apoio" aos processos educativos.

\section{- Biblioteca: o dispositivo informacional educativo e a ordem dialógica}

Os dispositivos, como o próprio nome diz, dispõem, isto é, ordenam, organizam, prescrevem (HOUAISS, 2001, p.1057). De modo abrangente, a noção de dispositivo de informação refere-se a todo e qualquer mecanismo (técnico, social e simbólico) capaz de promover a relação, organizar a realidade e fornecer um instrumento para o pensamento (um texto, uma mensagem fotográfica, cinematográfica, um ambiente, uma prática). Como conjunto de elementos intencionalmente articulado, o dispositivo cria uma ordem, que produz significados, no interior do qual o sujeito opera. O dispositivo é, assim, um signo, mecanismo de intervenção sobre o real, que atua por meio de formas de organização estruturada, utilizando-se de recursos materiais, tecnológicos, simbólicos e relacionais, que atingem os comportamentos e condutas afetivas, cognitivas e comunicativas dos indivíduos (PIERUCCINI, 2004, p. 43).

As bibliotecas tomadas, portanto, como dispositivos informacionais ao interferirem sobre a matéria básica com que lidam - as informações - criam sistemas que funcionam como códigos aplicados à sua ordenação e comunicação: não são meros suportes isentos, não apenas disponibilizam a informação, mas dizem, contam, narram: produzem significados (PIERUCCINI, 2004, p. 58).

Os efeitos dos dispositivos, desses meios dirigidos, ultrapassam, como se percebe, os limites técnicos visíveis -sua contingência- para tornarem-se instrumento da relação conosco, com os outros e com o mundo. Nesses termos, os comportamentos culturais contemporâneos (como visitar museus, navegar na internet, ir à biblioteca) são formas de atuação com e nos dispositivos, orientadas por regras e leis próprias dos meios em que se encontrem. 
Isto permite dizer que as relações dos sujeitos com a Informação e o Conhecimento, matérias com as quais a biblioteca lida, podem variar, ser redefinidas, contando-se com a participação de dispositivos culturais, especialmente configurados para tanto. Compreendida como dispositivo, a biblioteca na atualidade torna-se importante instância de mediação - de diálogo- dos sujeitos com a Informação, o Conhecimento e a Cultura. Assim, mais que servir de fonte de informações (nada desprezível, aliás), em tempos contemporâneos a atualização da biblioteca passa pela perspectiva de uma atuação que sirva para que os sujeitos possam, queiram e saibam estabelecer relações significativas com o universo simbólico existente. Contrariamente, as dificuldades e resistências apresentadas pelos alunos diante do dispositivo informacional, via de regra, decorrem de situações em que prevalece uma ordem monológica, que transforma implicitamente a biblioteca (e seus congêneres) em dispositivos ininteligíveis, distantes e, por vezes, obsoletos à grande maioria da população brasileira. Em decorrência, o interesse pela pesquisa, pelo desenvolvimento do espírito e a autonomia investigativos, de acordo com o que abordamos, estarão diretamente implicados com as bibliotecas e seus princípios norteadores.

Face a isso, instituir a dialogia (BAKHTIN, 1995; BRAIT, org., 2005; 2006; 2009), como critério organizador da ordem informacional dos dispositivos (bibliotecas), especialmente nos contextos educativos, implicará, objetivamente, rever concepções, configurações, práticas informacionais e pedagógicas, tendo em vista os diferentes grupos que os constituem. $O$ desenho do dispositivo informacional educativo, sob bases dialógicas, considerará a biblioteca escolar, por exemplo, como Estação do Conhecimento (PERROTTI; VERDINI, 2008), a ser transformada de modo dinâmico, no jogo entre especialistas/bibliotecários, instituição, corpo técnico-pedagógico, alunos e demais elementos da comunidade. Da negociação entre os diferentes protagonistas se define e se redefine permanentemente o formato do dispositivo informacional educativo, elemento chave aos pressupostos e caráter da pesquisa significativa. 
Fica claro, portanto, como lembra Chartier (2002), que a visão idealista, segundo a qual o conhecimento depende exclusivamente do domínio de conteúdos, não se sustenta diante das evidências sobre o papel dos dispositivos nos atos e na significação do conhecimento, como comprova a fala de um adolescente, expressando sua experiência em biblioteca, orientada segundo premissas aqui apresentadas:

A gente pesquisa por pura vontade da gente, porque a gente tem alegria em ver isso daqui... (Aluno, $6^{a}$ série)

\subsection{Pesquisa escolar significativa: biblioteca e o conhecer o conhecimento ${ }^{2}$}

A noção de pesquisa escolar como busca significativa, de acordo com perspectivas da Infoeducação, funda-se na ideia de que a construção de conhecimento implica conhecer o conhecimento e, neste sentido, os dispositivos informacionais educativos, pautados pela dialogia, visam favorecer processos sistemáticos e/ou assistemáticos de apropriação cultural, favorecendo e dando concretude aos saberes e fazeres demandados na relação com os signos.

Assim, as noções-padrão que via de regra orientam a pesquisa, determinando as sequências pelas quais o processo deve se desenvolver, são recontextualizados quando se trata de perspectivas dos dispositivos informacionais educativos, pautados pela Infoeducação.

Os passos da pesquisa, preconizados de modo mais ou menos similar por metodologias e programas de orientação à pesquisa, a saber, Identificação do assunto/objeto de interesse e da pergunta mobilizadora a ser respondida pela pesquisa (análise do trabalho a ser executado; levantamento dos conhecimentos prévios; contextualização do objeto; escolha do foco da pesquisa: a discussão com o grupo; elaboração de um esboço provisório e de um plano de trabalho); Busca das fontes de informação

\footnotetext{
${ }^{2}$ As sínteses aqui apresentadas estão fundadas em trabalho de pesquisa, realizado a partir de projeto de constituição de uma biblioteca escolar de ensino fundamental I. Disponível em: http://www.teses.usp.br/teses/disponiveis/27/27143/tde-14032005-144512/pt-br.php
} 


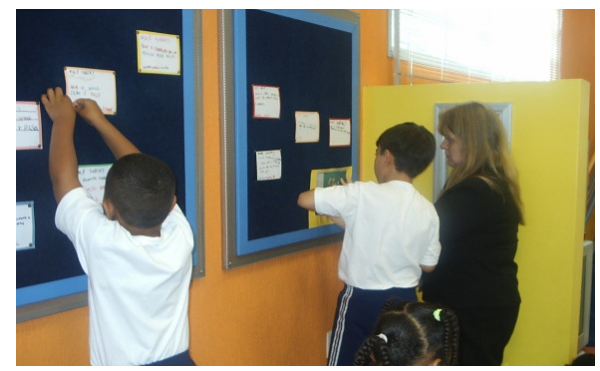

(identificaç

ão das

fontes e

ferramenta

S

necessária

s; captura de informações por meio de

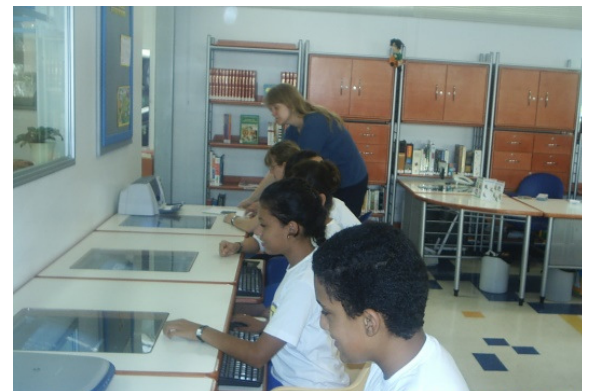

palavras-chaves; busca dos documentos que parecem pertinentes); Seleção dos documentos (classificação e seleção dos documentos obtidos; identificação dos conteúdos necessários; anotação das referências); Seleção das informações (leitura rápida dos documentos; leitura atenta dos documentos; classificação das anotações e revisão do plano provisório); Tratamento da informação (análise das informações coletadas; reflexão face ao problema proposto no trabalho); Comunicação dos resultados (redação do trabalho; verificação das informações anotadas; citação das fontes; revisão geral do trabalho) ganham significados próprios atribuídos pelos sujeitos, ao longo de processos frequentes, diversificados, orgânicos, sistemáticos de relação com os signos. Práticas concretas, contextualizadas, dinamizadas pelos alunos individualmente ou em grupo, conforme possibilidades individuais, fazem avançar e superar limites no complexo jogo de produção de conhecimento que, como se sabe, não se dá de modo linear, mas de forma crescente, com avanços, por vezes recuos, numa espécie de luta entre os sujeitos e as resistências inerentes à matéria simbólica.

\section{- A ordem do ambiente e a pesquisa significativa}

Fotos 1 a 10 - alunos
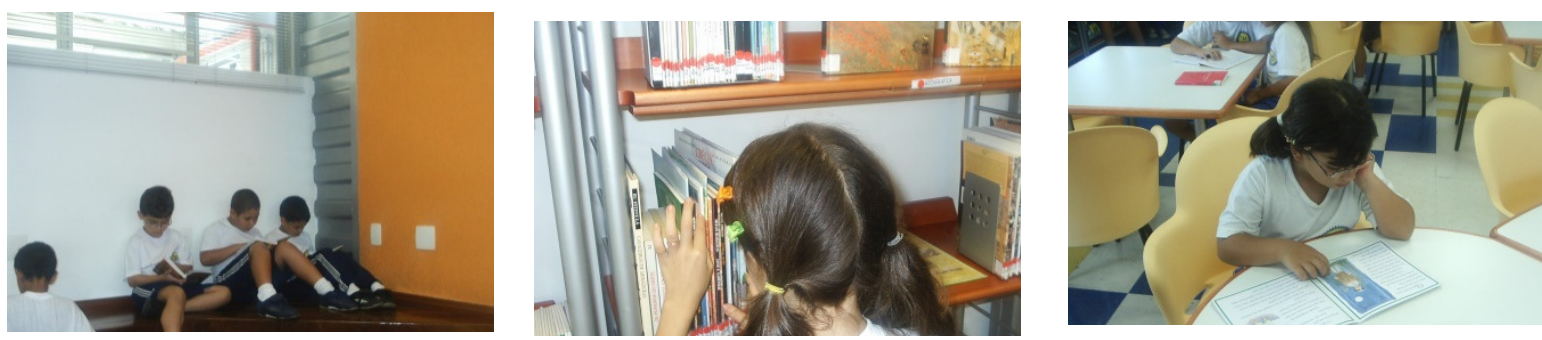

de biblioteca escolar em processo de pesquisa 




Fonte:


imagens do autor

Elementos constitutivos do ambiente físico, dentre os quais, estética/beleza, conforto, dimensões, organização espacial interna, a partir de critérios que facilitem a locomoção, o acesso livre, as interações entre áreas, práticas e pessoas (PIERUCCINI, 2004, p. 62-83) são itens que se agregam ao processo informacional, atuando no jogo entre a percepção, o processamento e a reelaboração de informações. Estimulando o gosto de ficar na biblioteca, as trocas e colaborações entre os diferentes sujeitos (crianças-jovensmediadores) e suas experiências, a pesquisa significativa é ato de conhecimento para além da apreensão de conteúdos, inscrevendo-se em processos pelos quais o conhecimento é construído. Conhecer é produzir novos significados e o ambiente informacional na perspectiva assinalada mostra-se categoria que contribui para o acolhimento dos sujeitos, criação de interesses pessoais e coletivos. A familiaridade com a biblioteca, repercutindo 
sobre a indispensável proximidade que favorece a construção de uma cultura do conhecimento, redefine e alimenta novas relações com o conhecimento e a cultura.

Como sugerido pelas imagens, a pesquisa escolar significativa, inscrevese numa dinâmica de aprendizagens informacionais, isto é, dos saberes acerca dos modos e lógicas pelas quais a informação se objetiva nos dispositivos, como é produzida, circula e como fazemos para usá-la adequadamente; ao mesmo tempo, alimenta-se de conteúdos "sobre alguma coisa" que se deseja conhecer. Nesse sentido, o dispositivo precisa estar preparado, em termos físicos, infraestruturais, para as movimentações demandadas nos processos que levam os sujeitos a identificar e definir o que pretendem conhecer, a buscar diferentes fontes de informação, a ler e selecionar documentos, a analisar, comparar e anotar informações, a discutilas e sintetizá-las, tendo em vista produzir novos conhecimentos, partilhandoos com o grupo. A corporalidade, a dinâmica de circulação, a gestualidade de quem busca autonomamente é, até mesmo, imprevisível e não controlada. Se biblioteca era tida como um lugar privilegiadamente de "livros", ela é, na perspectiva da pesquisa escolar significativa, um lugar material e imaterial, para pessoas em suas intensas dinâmicas pelo conhecimento.

Numa biblioteca normal assim, você não pode trocar ideia com um amigo, entendeu? Aqui você pode pedir uma opinião do colega seu, da professora. Daí você pode ter mais ideias, vêm mais ideias na cabeça. (Aluno, $6^{\mathrm{a}}$ série)

(...) Assim é mais confortável estudar. Tem o pufe, o computador para fazer pesquisa, dá até pra gente se divertir um pouco aqui. E aí a gente relaxa, ao invés de ficar naquela pressão de tem que fazer isso, tem que fazer aquilo. Aqui não precisa disso, aqui você vem pra pesquisar, mas se você quiser pesquisar na outra aula, você pesquisa". (Aluno, $6^{\mathrm{a}}$ série)

\section{- Repertórios, ordem informacional e a pesquisa significativa}

Os diferentes acervos (impressos, audiovisuais, digitais) em suas diversificadas modalidades (livros, periódicos, videos, sites etc) e as respectivas e particulares formas e lógicas pelas quais apresentam-se são 
elementos essenciais à pesquisa significativa. De fato, a familiaridade com a ordem que regula a produção e circulação da informação, ou seja, "os discursos" pelos quais esta é apresentada, constituem chaves aos processos de diálogo com a memória cultural universal. A convivência com um conjunto vivo e dinâmico de informações, com representações de diferentes contextos histórico-sociais, permitem o reconhecimento da diversidade de recursos informacionais, da abrangência de conteúdos, da diversidade de gêneros de informação, da diversidade e qualidade das obras, dos recursos eletrônicos como fonte de busca para produção de conhecimento, configuram possibilidades de contato com perspectivas e pontos de vista distintos e variados sobre os modos de representar a realidade e de chances de compreendê-la de modo mais abrangente.

Por esta razão, os repertórios pautados na produção reconhecida e consagrada pela cultura, serão compartilhados com a produção local, dado que, como resultados de processos de buscas significativas, tal produção resulta e se constitui como forma de expressão dos sujeitos e não mero exercício para aprender a fazer a pesquisa, simples ensaios de assimilação de metodologias.

Fotos 11 a 13 - Sistema de organização e sinalização em biblioteca escolar

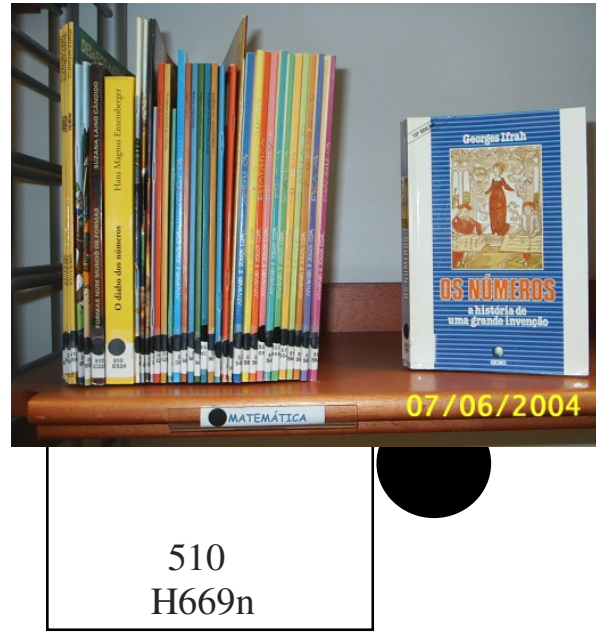

Fonte: imagens do autor

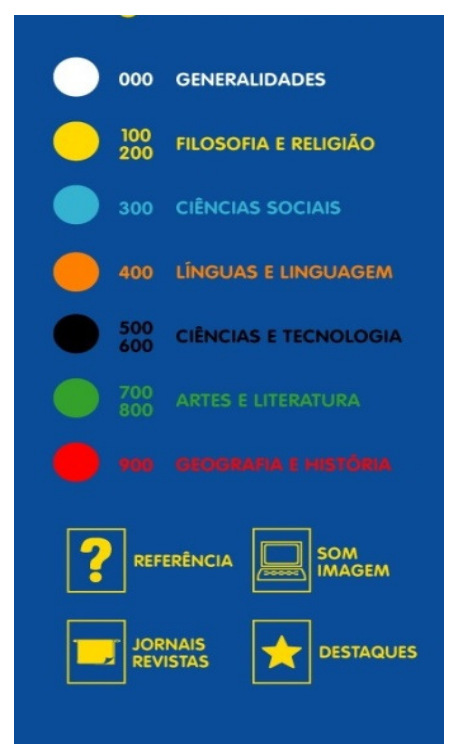


As linguagens informacionais especializadas (conforme imagens acima), na perspectiva da pesquisa significativa, não se prestam somente a questões técnico-funcionais, de localização dos materiais no acervo. Adotadas para dar organicidade aos conjuntos documentários e informacionais, nos dispositivos informacionais educativos são elementos que contribuem para que as crianças e jovens - e também adultos - se apropriem da ideia e aprendam - por experiência- que o conhecimento se estrutura de diferentes formas, que possui uma "ordem física e simbólica", é hierarquizado e, como todas as demais linguagens, é representação, não "a coisa em si". Portanto, oferece possibilidades, revela, mas também as esconde... Esses são alguns dos aspectos que impõem resistências quando se pretende o efetivo diálogo com a matéria que veiculam. Assim, a autonomia de percurso nas diferentes infovias de informação e cultura implica conhecer não apenas a informação, o conhecimento, mas, sobretudo a meta informação, o meta conhecimento, instâncias que sobrepõem significados aos significados dos repertórios existentes. Conforme alerta Bernstein (1977, apud USHERWOOD, 1989, v) "a forma como uma sociedade seleciona, classifica, distribui, transmite e avalia o conhecimento educativo que considera público reflete tanto a distribuição do poder como os princípios do controle social". Portanto, as opções em relação aos modos de ordenar fisicamente os objetos informacionais, os sistemas de classificação e respectivas linguagens adotados, os discursos usados nas sinalizações orientadoras dos sujeitos no dispositivo informacional educativo, bem como os produtos informacionais construídos por eles para organizar e orientar seus usos (bases de dados, sistemas de informações administrativas e culturais, dentre outros), extrapolam sua dimensão material, evidenciando que a representação do conhecimento é categoria de significação, que atua sobre a ordem do conhecimento, integrando-se aos processos da pesquisa

${ }^{3}$ USHERWOOD, B. A biblioteca pública como conhecimento público. Lisboa: Editorial Caminho, 1989. 
significativa. Construir meios que favoreçam conhecer as linguagens e lógicas da ordem informacional mostra-se, portanto, questão que se impõe à ação profissional dos bibliotecários-mediadores.

Outra hora, encontrei um livro na parte de Ciências porque, pensando bem, água depende muito de Ciências. Água é uma matéria de Ciências, então, eu encontrei mais pela organização. (Aluno, $6^{\mathrm{a}}$ série)

\section{- Mediações e mediadores e a pesquisa significativa}

Além das concepções e das materialidades que integram o conjunto de elementos que implicam a pesquisa significativa, mediadores e mediações interpessoais desempenham também importante papel no estabelecimentos de relações dos sujeitos com o dispositivo informacional, com outros sujeitos (pares e mediadores), com o universo informacional mais amplo, com a cultura. Nesse sentido, não é possível considerar um elemento mais importante que outro, mas, ao contrário, compreender que é do diálogo entre eles que a construção de significados ao ato de buscar, pesquisar, conhecer tem chances de se consolidar nos sujeitos. Mediadores e mediações, categorias intrínsecas a qualquer processo cultural, nem sempre tiveram sua importância educacional destacada e compreendida em sua essencialidade, reduzindo-se a mediação à categoria meramente funcional ou instrumental, ao "fazer aceder um público a obras (ou saberes)" ou "construir uma interface entre esses dois universos estranhos um ao outro" (DAVALLON, 2004; PERROTTI; PIERUCCINI, 2015). A compreensão dos sentidos encerrados na noção de mediação cultural como ato de significação (BRUNER, 1997), todavia, representa e contribui para sua redefinição no contexto do dispositivo informacional educativo.

Em relação aos mediadores (bibliotecários e professores, sobretudo) e seus respectivos desempenhos, não somente o domínio técnico-especializado e/ou pedagógico e os saberes especiais, mas atitudes, são fundamentais aos processos de apropriação do dispositivo e das dinâmicas capazes de transformar a pesquisa escolar em ato significativo. Como mediador, o sujeito terá de compreender o que está em jogo no processo de inserção dos mais 
jovens no universo da informação e do conhecimento. Seu papel será o de construir meios que viabilizem as complexas transições a serem feitas quando 0 ato de conhecer passa a ser marcado por signos e não necessariamente pelas relações diretas entre crianças e jovens e o mundo concreto.

Nesse quadro, características do mediador cultural, tais como, afetividade, sensibilidade, flexibilidade, disponibilidade e interesse, organização, domínio dos repertórios, domínio de tecnologias e demais recursos informacionais articulam-se a práticas intrínsecas ao dispositivo informacional educativo, tais como práticas de gestão, cujos objetivos pressupõem o estabelecimento de planos e processos articulados a princípios de iniciação dos mais jovens no universo informacional, de tal forma que se apropriem do contexto da pesquisa. Esses planos e projetos referem-se aos indispensáveis processos de manutenção da materialidade do dispositivo (organização dos acervos, sua circulação, de princípios de uso partilhado do espaço e demais desdobramentos inerentes às funções informacionais do dispositivo), partilhando com a comunidade a tomada de decisões, respeitando e informando acerca de programações, escalas, combinados. Nesse sentido, a ação do bibliotecário-mediador visará, sobretudo, a busca de meios de comunicação com os circuitos envolvidos, tendo em vista ir além da cristalizada noção de "administração da unidade de informação", inscrevendo tais práticas no âmbito das relações sujeitos-informação-cultura.

Práticas informacionais e culturais, por sua vez, que visam possibilitar diferentes experiências em relação aos atos de explorar, conhecer e reconhecer a diversidade informacional existente, suas distinções, especificidades e resistências, propõem caracterizar o dispositivo informacional educativo - a biblioteca- como espécie de oficina informacional, capaz de alargar os horizontes de percepção e de conhecimento da criança e do jovem sobre o campo da Informação. Atividades informacionais e culturais são atributos que se agregam às formas de construir e encorajar as indispensáveis relações de proximidade com a biblioteca e com a matéria simbólica que estão na base da pesquisa significativa.

Aqui, é tranquilo eu me expor, é tranquilo eu dividir, e isso acaba contagiando a escola inteira. Eu percebo que se eu 
tivesse essa oportunidade lá atrás, hoje muitas coisas se resolveriam, esse medo que a gente tem, essa insegurança de escrever, de arriscar em algumas coisas. Até aquelas crianças que são assim bem mais tímidas, aqui ninguém está preocupado em perceber essa questão, ele é livre pra fazer, pra ousar. (Professora, $1^{\text {a }}$ série)

\section{CONSIDERAÇÕES FINAIS: pesquisa significativa e o bibliotecário mediador}

A pesquisa significativa implica referências que possam fazer frente a situações em que crianças e jovens realizam buscas esvaziadas de sentido, restituindo ao ato de conhecer dimensões que lhe são tradicionalmente atribuídas, ou seja, ação sobre o mundo material e imaterial, objetivo e subjetivo, forma ativa e necessária à construção de conhecimentos, de sentidos, de identidades. Mais do que domínio de operações eficazes, trata-se de considerar a pesquisa e atos de conhecimento como processos mentais e culturais mutuamente implicados e que existem em permanente negociação no palco social.

Nesse sentido, os dispositivos informacionais educativos têm papel essencial nos processos geradores de interesse pelo conhecimento, por meio do acolhimento físico, intelectual e cultural dos alunos, implicando obrigatoriamente diferentes mediações, uma vez que a noção de pesquisa, aqui vislumbrada, constitui processo complexo de construção de significados, que inclui processamento de informação e criação de conhecimento sem, todavia, reduzirem-se uns aos outros.

$\mathrm{Na}$ pesquisa significativa, encontram-se em movimento dialógico relações entre os objetos, relações entre sujeitos e objetos, entre interlocutores culturais, dinamicamente articulados. Ler, pesquisar, conhecer, produzir informações e conhecimentos são operações que exigem importantes investimentos intelectuais, afetivos, emocionais, dentre outros, interrogar posições, questionar premissas, negar o que está "firmado nas escrituras", recriá-las, isto é, processos nada fáceis, gradativos, heterogêneos, muitas vezes lentos, demandando concepções e práticas claras, orgânicas, sistemáticas. 
Esta direção engendra requalificação teórica e prática da pesquisa escolar, na qual o bibliotecário mediador ocupa posição autônoma de criação dos meios ao diálogo que refletem sobre as relações entre Sujeitos e Informação/Conhecimento, a partir dos elementos de sua esfera de atuação: o espaço, os repertórios, as linguagens e práticas informacionais que constituem o dispositivo.

Trata-se de mudança paradigmática que introduz novas perspectivas, tanto às bibliotecas escolares e públicas (especialmente), quanto ao bibliotecário. Tais transformações não se restringem à mera exterioridade, concebendo-se a ordem do dispositivo informacional educativo numa perspectiva dinâmica, aberta, negociada que ao se constituir, constitui os sujeitos que dela participam. Sob os referenciais da Infoeducação, informação, conhecimento, sentido, significado combinam-se, complementam-se, rearticulam-se sendo o bibliotecário mediador e suas mediações um dos eixos para vislumbrarmos a possibilidade de uma existência significativa nos quadros culturais, muitas vezes caóticos, da contemporaneidade.

\section{REFERÊNCIAS}

BAKHTIN, M. Marxismo e filosofia da linguagem. São Paulo: Martins Fontes, 1995.

BRAIT, B. (Org.). Bakhtin: conceitos-chave. SP: Contexto, 2005.

BRAIT, B. (Org.). Bakhtin: outros conceitos-chave. SP: Contexto, 2006.

BRAIT, B. (Org.). Bakhtin: dialogismo e polifonia. SP: Contexto, 2009.

BRUNER, J. Atos de significação. Porto Alegre : Artes Médicas, 1997.

BURKE, P. Entre buscar e pesquisar: destaca os desafios dos bibliotecários em contextos acadêmicos. Entrevistadoras: Maria Aparecida Moura e Carla Pedrosa. Entrevista concedida em 17 novembro 2014. Bibliotecas universitárias: pesquisas, experiências e perspectivas. Belo Horizonte, v. 2, número especial, p. 80-90, fev. 2015.

CHARTIER, R. Os desafios da escrita. São Paulo: Ed. UNESP, 2002. 
DAVALLON, J. La médiation: la communication en procès? Médiations \& Médiateurs, n. 19, fev. 2004. Disponível em: http://www.mei-info.com/wpcontent/uploads/revue19/ilovepdf.com split 3.pdf Acesso em: 18 jul. 2011

HOUAISS, A. Dicionário Houaiss da língua portuguesa. Rio de Janeiro: Objetiva, 2001.

OLIVEIRA, A. L. A negociação cultural: um novo paradigma para a mediação e a apropriação da cultura. São Paulo. 2014. 250f. Tese (Doutorado em Cultura e Informação) - Escola de Comunicações e Artes, Universidade de São Paulo, São Paulo.

OLIVEIRA, I. R. de; CAMPELLO, B. S. Estado da arte sobre pesquisa escolar no Brasil. Transinformação, Campinas, v. 28, n. 2, p. 181-194, ago. 2016. Disponível em:<http://www.scielo.br/scielo.php?script=sci arttext\&pid=S0103-



PERROTTI, E. Infoeducação: um passo além científico-profissional (no prelo).

PERROTTI, E.; PIERUCCINI, I. Infoeducação : saberes e fazeres da contemporaneidade. In : LARA, M.L.G, FUJINO, A. NORONHA, D.P. (orgs) Informação e contemporaneidade: perspectivas. Recife : Néctar, 2008.p.4697. Disponível em: http://www3.eca.usp.br/sites/default/files/form/ata/pos/ppgci/publicacoes\%20\%20informacaoContemporaniedade(1).pdf . Acesso em: 18 jun. 2016.

PERROTTI, E.; PIERUCCINI, I. Novos saberes para o século XXI. In: MENDONÇA, R.H.; MARTINS, M. F. (orgs.). Novos saberes para a Educação. Rio de Janeiro : ACERP ; Brasília, DF : TV Escola, 2013. p. 9-25 (TV, educação e formação de professores: salto para o futuro 20 anos, 4) Disponível em:

http://tvescola.mec.gov.br/images/stories/publicacoes/salto para o futuro/salto 20 anos/vol 4 salto para o futuro 20 anos.pdf. Acesso em: 20 fev.2014

PERROTTI, E; PIERUCCINI, I. A mediação cultural como categoria autônoma. Informação \& Informação. Londrina, v. 19, n. 2, p. 01-22, out. 2014. Disponível em:

<http://www.uel.br/revistas/uel/index.php/informacao/article/view/19992>. Acesso em: 05 mar. 2015.

PERROTTI, E.; VERDINI, A. Estações do Conhecimento: espaços e saberes informacionais. In: ROMÃO, L.M.S. org. Sentidos da biblioteca escolar. São Carlos: Alphabeto, 2008. p. 13-40

PIERUCCINI, I. A ordem informacional dialógica: estudo sobre a busca de informação em Educação. São Paulo. 2004. 194f. Tese (Doutorado em Ciência da Informação) - Escola de Comunicações e Artes, Universidade de São Paulo, São Paulo. 


\title{
Title
}

Significant school research and the librarian: a key issue for the Infoeducation

\begin{abstract}
:
Introduction: The school research and the difficulties to make it qualified and effective practice in the daily lives of children and youth education in our country, it is a recurring theme for both librarians, and for teachers and other educators in general.

Objective: From the questioning of approaches that link causes of pedagogical and methodological for such difficulties, the paper presents and defends the concept of significant research, a concept that broadens perspectives of research as an act of knowledge by various children and youth segments.

Methodology: Anchoring is in the foundations of Infoeducation, the significant research concept is discussed from the essential role of educational and informational devices as the role of the librarian, taken as a cultural mediator.

Results: The study showed that significant research is directly related to so-called dialogic information devices, since such instances of cultural mediation, being guided by principles of information appropriation, as proposed by Infoeducação, are capable of reframing the subjects' relations with information and knowledge. The resulting order of the links between environment, languages, repertoires, informational and educational practices, in these devices, constitute mediations that favor processes of bond building between the subjects and the knowledge, involving specifically the knowledge and practices of the contemporary librarian.

Conclusions: The notion of significant research in the face of situations where children and young people perform searches empty of meaning, restores knowledge to its role of acting on the material and immaterial world, objective and subjective, in an active and necessary form for the appropriation of information, meanings, and the construction of identities. It is about a paradigmatic change that involves the redefinition of educational informational devices, such as school and public libraries (especially), as well as the role of the librarian in educational settings.
\end{abstract}

Keywords: Research school; Significant Research; Infoeducation; Library School; Cultural mediator; Educational informational devices.

\section{Título:}

Investigación escolar significativa y el bibliotecario: cuestión esencial para la Infoeducação

\section{Resumen}

Introducción: La investigación escolar y las dificultades para convertirla en práctica calificada y efectiva en la educación cotidiana de niños y jóvenes es, en nuestro país, un tema recurrente no solo para bibliotecarios sino también para profesores y otros educadores, en forma general.

Objectivo: A partir de la problematización de enfoques que señalan causas de orden pedagógica y metodológica para dichas dificultades, el artículo presenta y defiende el concepto de investigación significativa, noción ésta que ensancha las perspectivas de la investigación como acto de conocimiento a través de los más variados segmentos infantiles y juveniles.

Metodología: Con base en los fundamentos de la Infoeducación, la noción de investigación significativa se discute a partir del rol esencial que desempeñan los 

infoeducação

dispositivos informacionales educativos y del bibliotecario, considerado como mediador cultural.

Resultados: El estudio mostró que la investigación significativa está directamente relacionada con los llamados dispositivos de información dialógica, ya que tales instancias de mediación cultural, guiados por los principios de apropiación de información, propuesto por Infoeducação, son capaces de reenmarcar las relaciones de los sujetos con información y conocimiento. El orden resultante de los vínculos entre el medio ambiente, las lenguas, los repertorios, las prácticas informativas y educativas, en estos dispositivos, constituyen mediaciones que favorecen los procesos de vinculación entre los sujetos y el conocimiento, involucrando específicamente los conocimientos y prácticas del bibliotecario contemporáneo.

Conclusiones: La noción de investigación significativa frente a situaciones en las que los niños y jóvenes realizan búsquedas vacías de sentido, restablece el conocimiento a su función de actuar sobre el mundo material e inmaterial, objetivo y subjetivo, en forma activa y necesaria para la apropiación De la información, los significados y la construcción de identidades. Se trata de un cambio paradigmático que implica la redefinición de dispositivos informativos educativos, como la escuela y las bibliotecas públicas (especialmente), así como el papel del bibliotecario en entornos educativos.

Palabras Clave: Escuela de investigación; Investigación Significativa; Infoeducación; Escuela de la Biblioteca; Mediador cultural; Dispositivos educativos informativos.

Recebido em: 25.08.2016

Aceito em: 30.11.2016 